\title{
NEWS FROM THE GDC
}

It appears the GDC have been extremely

busy this month clamping down on illegal

tooth whiteners. In the space of five weeks,

five different individuals were successfully

prosecuted for unlawfully practising dentistry

- namely tooth whitening.

Natalie Kowalczyk from Jo and Cass

Beauty Salon in Lancaster, Victoria Reeve

from The Nail Bar in Halstead, Jade Hayes

from LA Hair Extensions, Nottingham, Julie

Marino, Director of The Teeth Whitening

Company and Sam Wellman in Leeds were

all prosecuted.

And they say the ARF is too expensive...!

Speaking of ARF, The GDC has launched a consultation on the level of its ARF for

dentists and dental care professionals in 2016.

While proposing that the ARF levels remain

the same as in 2015, the GDC is taking

this opportunity to conduct an exceptional

consultation to:

- Set out the financial and other information

on which the proposal is based

- Seek views on the proposed level of the fees.

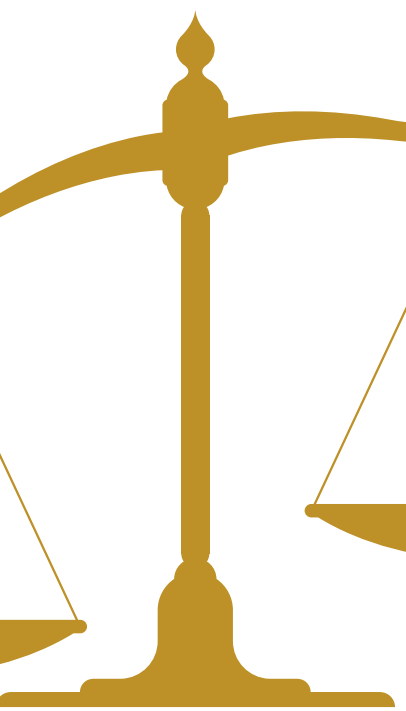

Based on 'projections of the levels of complaints' - which they believe will remain at recent peak levels - and sound financial modelling covering the work of the GDC, they are proposing that the ARF for 2016 remains the same as in 2015: $£ 890$ for dentists and $£ 116$ for dental care professionals.

Mick Armstrong, Chair of the British Dental Association responded by saying: 'The General Dental Council has announced a consultation on not changing their fees. We hope they aren't expecting us to take any comfort from this, as for 40,000 dentists 'business as usual' means another year shackled to the most expensive, and least effective health regulator in Britain.

'This latest announcement shows nothing has changed. Dentists are still paying double the average for UK health professionals. Registrants are still on the receiving end of the same one-sided conversation from a cavalier regulator, which continues to ignore its own failings.

'What we've not seen is any real willingness from a failed regulator to get on top of its day job, and to finally draw a line under years of mission creep. For our part we will be subjecting these numbers to forensic scrutiny. We encourage all colleagues to have their say, so we can see what GDC's commitment to 'transparency' and 'openness' really means.'

The GDC remains the most expensive healthcare regulator in the UK - at $£ 890$ its annual retention fee is more than twice the average professional fee - and it was recently identified as the worst performing regulator by the Professional Standards Authority in its Annual Performance Review.

\section{CQC: DENTAL SERVICES REMAIN LOW RISK}

The British Dental Association (BDA) has welcomed the latest Care Quality Commission (CQC) State of Care report, which has again revealed the low risk, good quality care delivered in English dental practices.

The CQC carried out 714 inspections of primary dental care services in 2014/15. It concluded that, compared to other sectors dental services present a lower risk to patients' safety, that the majority of dental services are safe and that the quality of care is good.
The low risk has prompted the CQC to move to a model of inspecting just 10 per cent of all practices each year.

Mick Armstrong, Chair of the BDA, said: 'In recent years we've seen a clear and consistent picture emerge from inspections by the CQC. The care provided by dental services combines low risk and good quality which is something our profession has always known. It's also a reminder why the new approach to dental inspections was the right choice.'

\section{Global oral health burden amoamts to $\$ 442$ billion}

Improvement in oral health alone can offer the world substantial economic benefit as researchers have estimated that the yearly global economic impact of dental diseases amount to $\$ 442$ billion.

The research by Stefan ListI from Heidelberg University in Germany, and colleagues estimated that the direct treatment costs due to dental diseases worldwide were at $\$ 298$ billion yearly, corresponding to an average of $4.6 \%$ of global health expenditure.

In addition to treatment costs, there are indirect costs to consider, mainly in terms of productivity losses due to absenteeism from work.

Indirect costs due to dental diseases worldwide amounted to \$144 billion yearly, corresponding to economic losses within the range of the 10 most frequent global causes of death.

While estimation of direct treatment costs was based on a systematic approach, for estimation of indirect costs, an approach suggested by the World Health Organisation's commission on macroeconomics and health was employed.

This approach factored in 2010 values of gross domestic product per capita as provided by the International Monetary Fund and oral burden of disease estimates from the US Global Burden of Disease Study.

'Through this study, the authors have amplified the message that we need to increase the availability of internationally comparable data on dental treatment costs, disease-specific absenteeism from work and school, as well as intangible costs of oral diseases in terms of quality of life', said Timothy DeRouen, former president of American Associations for Dental Research (AADR).

The research, published by AADR and International Associations for Dental Research (IADR), appeared online in the Journal of Dental Research. 